\title{
Comentario Editorial: La regulación de la Medicina prepaga: el mercado, el Estado y la discrecionalidad
}

Javier Vilosio *

\begin{abstract}
Resumen
En Argentina contamos por primera vez con una Ley que regula a las entidades de medicina Prepaga, que atienden a algo más de cinco millones de argentinos. Este marco regulatorio es un avance necesario, pero por supuesto, ha supuesto un debate sobre los límites entre Estado y Mercado (aunque no de la calidad deseable). Y es también una oportunidad para avanzar en nuevas alternativas de integración del sistema.

En gran medida algunos aspectos de la norma dejan abierto un amplio margen de discrecionalidad en su interpretación y su aplicación. Ello nos remite a la importancia de contar con las instituciones que prevé la organización republicana en tes Poderes independientes, en el contralor y la corrección de la misma.

\section{Abstract}

In Argentina, we have for the first time a law that regulates Prepaid medical institutions, serving over five million Argentines. This regulatory framework is a necessary development which, of course, has raised a debate about the boundaries between State and market (though not of desirable quality). It is also an opportunity to advance on new ways of integrating the health system.

To a great extent some aspects of the standard leave open a wide margin of discretion in their interpretation and application. This highlights the importance of control and feedback mechanisms of the institutions organized under our three branched, independent powered, republican system.
\end{abstract}

Palabras clave: medicina prepaga, leyes, mercado, política de salud, mercado de salud. Key words: prepaid medicine, law, marketing, health policy, health market. Vilosio J. La regulación de la Medicina prepaga: el mercado, el Estado y la discrecionalidad. Evid Act Pract Ambul. Oct-Dic 2011;14(4):122-123.

\begin{abstract}
Las empresas de medicina prepaga (EMP) reconocen su origen alrededor de los años ' 60 . Desde entonces se ha multiplicado el número de organizaciones que comercializan cobertura médica prepagada. Sus estructuras y modelos organizacionales son diversos: empresas comerciales, pero también instituciones $\sin$ fines de lucro, cooperativas, mutuales y obras sociales, algunas con alto grado de integración de servicios y otras que prácticamente no cuentan con prestadores propios. Varían sus coberturas territoriales y, por supuesto, su cartera de clientes. El servicio que ofrecen es similar a un seguro de salud (o, mejor dicho: de atención a la enfermedad), con diversas coberturas y precios.

Las cinco mayores organizaciones reúnen aproximadamente el $60 \%$ del total de los beneficiarios del sector: unos cinco millones de personas. Y probablemente un porcentaje aun mayor de la facturación total del subsector. El gasto privado en la contratación de estos seguros equivale al 1,46\% del $\mathrm{PBI} \mathrm{I}^{1}$.

Aproximadamente la mitad de sus beneficiarios ingresaron al sistema a partir de la desregulación de la Obras Sociales (OS), transfiriendo parcialmente sus aportes de la Seguridad Social al pago de la cuota de una EMP, a través de acuerdos establecidos con OS que ofrecen a los trabajadores, de su propio ramo de actividad o afiliados a otros Gremios, coberturas diferenciadas a cargo de una EMP.
\end{abstract}

Su funcionamiento hasta ahora se regía por la normas del Derecho general para los contratos, la Ley de Defensa del Consumidor en cuanto a los derechos de los usuarios, la Ley №24.754 -que las obliga a brindar como mínimo las prestaciones establecidas en el Programa Medico Obligatorio (PMO)-, y la Ley $N^{\circ} 24.455$-que les impone la cobertura de los pacientes afectados por HIV/SIDA, y la de los dependientes del uso de estupefacientes-. Se la consideraba, por ello, una actividad escasamente regulada.

Pero en mayo de 2011 se promulgó la Ley 26.682 que, tras varios años de demora en el trámite parlamentario, establece las reglas de juego para estas organizaciones**.

En diciembre el Poder Ejecutivo (PE) emitió el Decreto de Necesidad y Urgencia $N^{\circ} 1991$, que modifica el alcance de la
Ley sancionada en el Congreso, incluyendo bajo el mismo a las "...cooperativas, mutuales, asociaciones civiles y fundaciones cuyo objeto total o parcial consista en brindar prestaciones de prevención, protección, tratamiento y rehabilitación de la salud humana..." que habían quedado excluidas de la norma* ${ }^{* \star *}$

El paso dado por la Presidencia era necesario: nuestro sistema de salud es ya lo suficientemente atomizado como para sumarle aun más complejidad normativa. Se trata de organizaciones de tipos y estructuras diversas, lo cual sin duda sumará dificultad técnica a la actividad de la Superintendencia de Servicios de Salud (SSS), a quien el Ministerio de Salud delega las funciones de autoridad de aplicación, para lo cual deberá desarrollar una significativa capacidad técnica, hoy inexistente.

Simultáneamente el PE emitió el Decreto 1993 que reglamenta casi todos los artículos restantes. $Y$ deja planteados algunos interrogantes, que retomaremos sobre el final de estas líneas.

Lo cierto es que se concretó así un paso trascendente en el ordenamiento del sistema sanitario argentino, aunque, claro, no exento de polémica.

Si bien públicamente todos los actores reconocen la necesidad de regular la actividad, el trámite del proyecto de Ley reverdeció algunos debates referidos al "como" hacerlo: es decir, sobre los límites entre Estado y Mercado.

Aunque la adhesión a un plan de medicina prepaga implica el ejercicio de un acto voluntario entre particulares (beneficiarios o prestadores), no es menos cierto que la asimetría en la información expresada a través de clausulas en letra chica y de otros aspectos de los contratos, la posición francamente dominante de muchas EMP en el mercado, y el hecho de que las mismas capten recursos de la Seguridad Social, ameritan algún tipo de regulación que ordene dichas contrataciones.

Asi, dos argumentos -que resultan atendibles- fueron reiteradamente esgrimidos por representantes de las empresas en los últimos meses: por un lado, que gran parte de la demanda sobre el sector se origina en la insatisfacción de las personas en relación con la cobertura o la calidad de los servicios estatales o de la seguridad social. El mensaje era: ordenen "sus" servicios, y dejen

** En la Cámara de Diputados se aprobó con 190 votos a favor y 29 abstenciones. Fue votada favorablemente por el Frente para la Victoria, Nuevo Encuentro, Unión Cívica Radical, Partido Socialista, GEN, Proyecto Sur, y la mayoría del Peronismo Federal. Los diputados del sector de Francisco De Narváez del Peronismo Federal, el PRO y la Coalición Cívica se abstuvieron.

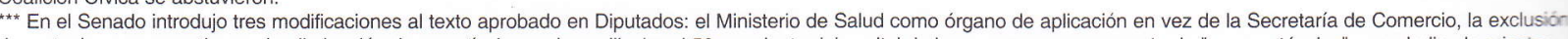
de mutuales y cooperativas, y la eliminación de un artículo que inmovilizaba el 50 por ciento del capital de las empresas en concepto de "reserva técnica" para dedicarlo a instrumentos financieros. Las mutuales y cooperativas fueron incluidas nuevamente por el PE, a través del DNU 1991/2011.

* Profesor Adjunto del Departamento de Salud Pública, Instituto Universitario Escuela de Medicina del Htal. Italiano de Buenos Aires. javier.vilosio@ @ospitalitaliano.org.ar 
a la medicina prepaga comercializando prestaciones de "lujo". El otro argumento, más de fondo, se refería a la necesidad de no quebrar la lógica del aseguramiento, base del negocio: las personas pagan en el tiempo presente por posibles necesidades a futuro, y esa es la base del sistema de exclusiones y preexistencias. Haciendo una analogía con el mercado automotor, se solicitaba que no las obligaran a aceptar la afiliación de "autos chocados". En algunos momentos del debate desde algunas posiciones extremas parecía ignorarse que la magnitud de la población atendida por las EMP se relaciona con el primero de los argumentos mencionados, y que mediante acuerdos con diversas Obras Sociales, aquellas se ven "beneficiadas" con esta transferencia de afiliados -naturalmente de mayores ingresos-. Esto significa en términos técnicos el "descreme" del sistema solidario, que debió ser protegido primordialmente por las propias Obras Sociales.

El artículo $10^{\circ}$ de la Ley concentró gran parte de los cuestionamientos desde el sector de las EMP. En el mismo se prohíben las carencias para las prestaciones previstas en el PMO, y se establece que para aquellas no incluidas éstas serán determinadas por la SSS.

Los dos artículos siguientes establecen que la edad no puede ser motivo de rechazo de una afiliación, y que la autoridad de aplicación establecerá los "porcentajes de aumento de costos según riesgo para los distintos rangos etarios" a partir de esa edad, y se prohíbe el aumento de las cuotas a aquellos mayores de 65 que tengan diez años de antigüedad en la EMP. Para los que no cumplan ese requisito la SSS definirá la matriz de cálculo actuarial de ajuste por riesgo.

En la reglamentación se estableció también que la SSS determinará una clasificación de las preexistencias en tres tipos: a) temporarias: patologías que tienen tratamiento predecible con alta médica a la brevedad; b) crónicas: aquellas en las que con el conocimiento científico disponible no se puede determinar una evolución clínica predecible ni el tiempo hasta el alta médica; y c) de alto costo y baja incidencia: aquellas en que el tratamiento pone en riesgo económico a las partes.

Para las preexistencias temporarias la SSS autorizará valores diferenciales en las que se justifique, así como la duración de ese pago (cuotas diferenciadas), que no podrá ser mayor a tres años. Para las crónicas y las de alto costo, se establece similar potestad aunque sin especificar tiempos de duración del cobro de cuotas diferenciadas.

Si la cuestión de la preexistencias parece haberse morigerado en la reglamentación, en cuanto a los motivos de rechazo de afiliación -que se prohíben- el decreto reglamentario va más allá de la ley, agregando a la edad lo establecido en el artículo $1^{\circ}$ de la Ley № 23.592 (de penalización de actos discriminatorios), la cual obliga a "dejar sin efecto, o reparar el daño moral y material ocasionado por cualquier acto que impida, obstruya, restrinja o de algún modo menoscabe el pleno ejercicio sobre bases igualitarias de los derechos y garantías fundamentales reconocidos por la Constitución Nacional", en temas tales como: raza, religión, nacionalidad, ideología, opinión política o gremial, sexo, posición económica, condición social o caracteres físicos.

El art. $17^{\circ}$ de la Ley se refiere a las cuotas de los distintos planes que ofrecen las EMP. Básicamente, la autoridad de aplicación fiscalizará y garantizará la razonabilidad de las cuotas y autorizará aumentos cuando estén fundados en variaciones de la estructura de costos y un razonable cálculo actuarial de riesgos. También autoriza la existencia de precios diferenciales para los distintos planes prestacionales, según franjas etarias y con una variación máxima de tres veces entre el precio de la primera y la última (la menos y la más onerosa, respectivamente).

El decreto reglamentario obliga a la SSS a establecer la estructura de costos que deberán presentar las EMP como requisito para solicitar que se les autorice un aumento de las cuotas. Dichas solicitudes deberán ser aprobadas también por la Secretaria de Comercio Interior (SCl).

No solo los costos pasarán por la revisión de la SSS: los modelos de contrato entre EMP y afiliados serán establecidos por ella.

Por otra parte, si bien el objetivo de la regulación son los beneficiarios del sector, también los prestadores de servicios contratados por las EMP tomaron debida nota de la discusión.

Para ellos los problemas fundamentales se vinculan con la informalidad de las contrataciones y los valores arancelarios impuestos en una negociación habitualmente muy asimétrica, particularmente frente a las grandes empresas en las ciudades más grandes.

Un importante sector de estos prestadores es dependiente de las EMP. Y el establecimiento de reglas de juego hasta ahora inexistentes también los movilizó en un intento por proteger sus intereses. Dos artículos de la Ley parecen haber resumido esas aspiraciones: el establecimiento de aranceles mínimos obligatorios, y la creación de un Consejo Permanente de Concertación, con representación de los Prestadores.

El debate previo a las votaciones en el Congreso no fue auspicioso, abundó en posturas principistas y declamaciones, y fue escaso en argumentaciones concretas, fundamentadas en hechos y números ciertos. El mismo día de su aprobación definitiva algunos legisladores reconocían en la intimidad la necesidad de correcciones y cambios, y que se había priorizado la necesidad política de "sacar" rápido la Ley. Aun con imperfecciones.

En cualquier caso, la regulación de las EMP es un paso positivo en el camino que debería seguirse para la integración del sistema sanitario. Algunos aspectos de la normativa claramente protegen a los usuarios, en un mercado nada "perfecto", y una actividad de alto impacto sanitario y social: su existencia e importancia son insoslayables. Como dijimos, casi cinco millones de argentinos reciben asistencia a través de la medicina prepaga.

De hecho, este podría ser el comienzo de nuevos cambios integradores, por ejemplo unificando el financiamiento de aquellas practicas económicamente catastróficas, permanente amenaza para la viabilidad de las EMP y especialmente con la nueva regulación, bajo un modelo de redistribución similar al que la Administración de Programas Especiales gestiona para las Obras Sociales, pero al cual pudieran integrarse tanto el sector público como las EMP, con sus respectivos aportes.

También es auspiciosa la integración del conjunto de los involucrados en la discusión de los aspectos operativos del marco establecido, aunque los límites de la integración del Consejo Consultivo y su funcionamiento permanecen difusos en la reglamentación.

En varios aspectos quedan abiertas alternativas muy amplias para la discrecionalidad de los funcionarios en la interpretación o aplicación de las normas, lo cual, en un contexto altamente politizado como el nuestro es un riesgo muy concreto.

El problema de la.discrecionalidad de los funcionarios se compensa en los regímenes republicanos con el juego independiente de instituciones de los tres poderes del estado, y la atenta vigilancia de la sociedad civil. En este aspecto, como en otros de nuestra vida social y política, la calidad de estas instituciones determinará si esta herramienta legal con la que hoy contamos verdaderamente ayuda a construir un mejor sistema de salud. 